REVIEW ARTICLE

\title{
Ultrasonographic findings in pelvic endometriosis: literature review and pictorial essay
}

\section{Achados ultrassonográficos na endometriose pélvica: revisão de literatura e ensaio pictórico}

Vitória Liz Taumaturgo da Costa ${ }^{1}$. Maria Beatriz Taumaturgo Moreira ${ }^{2}$. Luís Arthur Brasil Gadelha Farias ${ }^{3,4}$. Jesus Irajacy Fernandes da Costa ${ }^{4,5}$.

1 Centro Universitário Christus (Unichristus), Fortaleza, Ceará, Brasil. 2 Universidade Estadual do Ceará (UECE), Fortaleza, Ceará, Brasil. 3 Escola de Saúde Pública do Ceará (ESP), Fortaleza, Ceará, Brasil. 4 Universidade Federal do Ceará (UFC), Fortaleza, Ceará, Brasil. 5 Hospital Universitário Walter Cantídio (HUWC), Fortaleza, Ceará, Brazil.

\section{ABSTRACT}

The diagnosis of endometriosis can be made with some security when they exhibit typical aspects, using the various imaging methods. Ultrasonography is usually a cheap and accessible method that has high sensitivity and specificity in the diagnosis of endometriotic lesions. This article aims to describe the main findings in ultrasound of pelvic endometriosis with a focus on extra-uterine involvement.

Keywords: Endometriosis. Gynecology. Ultrasonography. Diagnostic imaging.

\section{RESUMO}

O diagnóstico de endometriose pode ser feito com alguma segurança quando exibem aspectos típicos, utilizando-se os diversos métodos de imagem. A ultrassonografia é um método barato e acessível que apresenta alta sensibilidade e especificidade no diagnóstico das lesões endometrióticas. O objetivo deste artigo é descrever os principais achados em ultrassonografia da endometriose pélvica com foco no acometimento extra-uterino.

Palavras-chave: Endometriose. Ginecologia. Ultrassonografia. Diagnóstico por imagem.

Corresponding author: Luis Arthur Brasil Gadelha Farias, Juazeiro do Norte Street, number 333, Meireles, Fortaleza, Ceará, Brasil. CEP: 60165110. Phone: +5585 99680-3802. E-mail: luisarthurbrasilk@hotmail.com.

Conflict of interests: The authors have no conflicts of interest to declare.

Received: 28 Jun 2020; Revised: 18 Aug 2020; Accepted: 24 Aug 2020. 


\section{INTRODUCTION}

Endometriosis is a common gynecological condition that can be polymorphic and multifocal usually characterized by the growth of endometrial-like tissue on the outside of the uterine cavity, more frequently on the ovaries, rectovaginal septum, bowel, bladder, ureters and peritoneum. The endometriotic lesions can cause a myriad of symptoms such as dysmenorrhea, dyspareunia, pelvic pain and infertility. ${ }^{1-4}$ Endometriosis reprensents a debilitating disease with features of chronic inflammation with fibrosis and inflammatory reaction. Furthermore, when the invasive tissue infiltrates adjacent structures at a depth of more than $5 \mathrm{~mm}$ from the peritoneal surface, deeply infiltrating endometriosis can be recognized. It is considered a disease that causes high morbidity, with important quality of life and psychosocial effects. It is estimated to affect up to $15 \%$ of the general female population, and observed in up to $60 \%$ of women with pelvic pain, being a major public health concern. ${ }^{3}$

The pathogenesis of endometriosis is complex and not completed understood, once it can be the result of diverse anatomical or biochemical aberrations of uterine function. Some factors are described to be related to the origin of endometriotic cells such as retrograde menstruation (during which endometrial fragments migrate through fallopian tubes), blood and lymphatic dissemination (endometrial cells travel through lymphatic or blood circulation), stem cells (endometriumderived progenitor cells in the basal layer are disseminated through the fallopian tubes to the peritoneal cavity), and metaplasia of coelomic epithelium (peritoneal mesothelial cells differentiate into endometrium-like tissue). The histologic origin of endometriosis is not a consensus. Sampson's proposal suggests that fragments from menstrual endometrium pass backward through the fallopian tubes and implant on peritoneal surfaces is plausible, but do not explain why only some but not the majority of women develop endometriosis, once reflux menstruation is present in most of the female population. ${ }^{4,5}$

A presumptive diagnosis of deeply infiltrating endometriosis may be developed through methods of imaging. Ultrasound is the first-line imaging method to evaluate endometrial lesions. $^{1-5}$ This pictorial essay aim to describe imaging findings of pelvic endometriosis on ultrasonography (US) and performed a literature review.

\section{METHODOLOGY}

\section{Procedure and patient preparation}

At the authors' institutions, the transvaginal US examination was performed by using US Toshiba`s Xario (transducer 5-9$\mathrm{MHz}$ frequency) after bowel preparation. The interpretation of each examination was made in real time by a radiologist with large experience identifying the endometriosis aspect in ultrasonography. Bowel preparation includes a mild laxative administered in two oral doses (at 8:00 am and 2:00 pm) the day before the scheduled transvaginal US examination, associated with a low-residue diet for 24 hours before the examination, and an enema (120 $\mathrm{mL}$ of sodium diphosphate) administered approximately 1 hour before the examination. The duration of the US examination is on average 30 minutes.

The technique used was based on the protocol defined by the International Consensus Group for the Analysis of Deep Endometriosis. ${ }^{6,7}$ The data collected on US are described in detail in the radiology report by systems.

\section{Limitations of transvaginal US}

The limited field-of-view may be the major limitation of transvaginal US, making the view of lesions located outside the pelvis difficult, notably above the rectosigmoid junction. Other frequent affections that may diminish lesion visualization are large ovarian cysts, subserosal leiomyomas, and acute retroflexion of the uterus. In addition, severe pelvic adhesions and other distortions of the pelvic anatomy may limit transvaginal US evaluation of the pelvic region.

\section{Bladder endometriosis}

Urinary tract endometriosis involves the bladder and/or the ureters. Bladder endometriosis is a specific form of endometriosis characterized and defined by the presence of stroma and endometrial glands in the detrusor muscle. It is found in approximately $1 \%$ of women affected by endometriosis, being the bladder the organ most frequently affected, accounting for $70-85 \%$ of cases. The base and the dome are the most frequently affected sites. In about $90 \%$ of cases at least one other site association has been reported (superficial peritoneal implants, ovarian endometriomas, adhesions and extravesical deep peritoneal endometriosis). ${ }^{8}$

The clinical symptoms vary and depend on the location and size of the lesion. The main symptoms are cyclical urgency, frequency, tenesmus, burning sensation, dysuria, suprapubic pain and discomfort with or without hematuria and dyspareunia, usually exaggerated during menses, often mimicking recurrent cystitis. ${ }^{9}$

Among the radiologic methods, transvaginal US is the most accurate imaging technique for diagnosing bladder endometriosis. It allows to determinate lesion size and depth of extension into the detrusor. The typical transvaginal US image of an endometriotic implant in the bladder is a midline, solid hypoechoic nodule with regular or irregular contours that adheres to the posterior aspect of the bladder dome (Figure 1). The internal appearance of the lesions varies depending on the presence and size of cystic areas within them. For a dynamic assessment of the posterior vesical wall, it is required the presence of a minimal amount of urine in the bladder. Hydronephrosis can be found as result of ureteral stricture secondary to endometrioses. ${ }^{1,2}$

The differential diagnosis of endometriotic lesions in the bladder includes urachal remnant and epithelial and mesenchymal tumors. 
Figure 1. Solid hypoechoic nodule with irregular contours on the posterior aspect of the bladder dome.

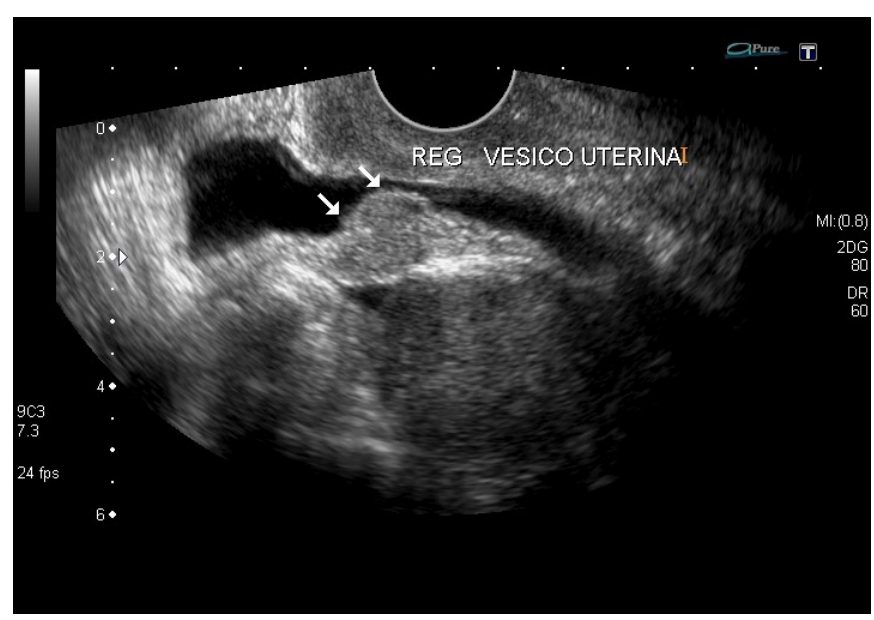

\section{Uterine serosa and round ligaments}

When the anterior uterine serosa and round ligament insertion are affected by endometriosis, they present with deeply infiltrating lesions with indistinct margins. ${ }^{1,2}$

At transvaginal US, when compared to the myometrium, these lesions are more hypoechoic and often contain multiple bright foci or small cystic areas that can be easily detect by ultrasonography (Figure 2). The differential diagnosis of small round lesions in this topography include subserosal leiomyoma. ${ }^{1}$

Figure 2. Uterine serosa envolved by endometriosis (arrows).

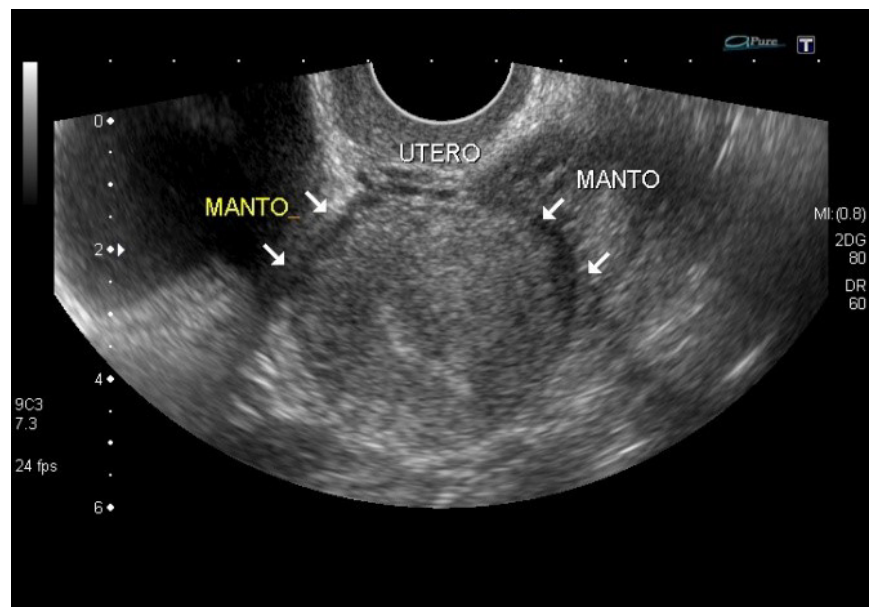

\section{Retrocervical region}

Retrocervical region is defined as the area situated right above the rectovaginal septum, and represent a virtual extraperitoneal space posterior to the cervix. This region is frequently affected by deeply infiltrating endometriosis. Endometriotic implants in this area are associated with uterosacral ligaments involvement and often causing obliteration of the pouch of
Douglas and uterine retroflexion. Multiple adhesions and distortion of pelvic anatomy resulting in a frozen pelvis are complications described in severe cases. ${ }^{10}$

The uterosacral ligament may be affected unilaterally or bilaterally. Asymmetry between the two ligaments, diffuse or localized thickening, and a nodule with a regular or stellate margin near the site of cervical uterosacral ligament insertion are among the morphologic abnormalities that may occur in patients with this affection. At transvaginal US, these lesions commonly appear hypoechoic, while uterosacral ligament nodules display as a mixed echotexture due to anechoic or hypoechoic cystic areas causing a heterogeneous appearance (Figure 3).

The most important differential diagnosis of retrocervical lesions are malignancies. Peritoneal metastases with origin in gastrointestinal tract and ovaries as the primary sites are the most common malignancies. Findings of ascites and a tumor mass in the abdominal cavity are highly suggestive of metastatic malignancies. ${ }^{11}$

Figure 3. Endometriotic implants with uterosacral ligaments involvement.

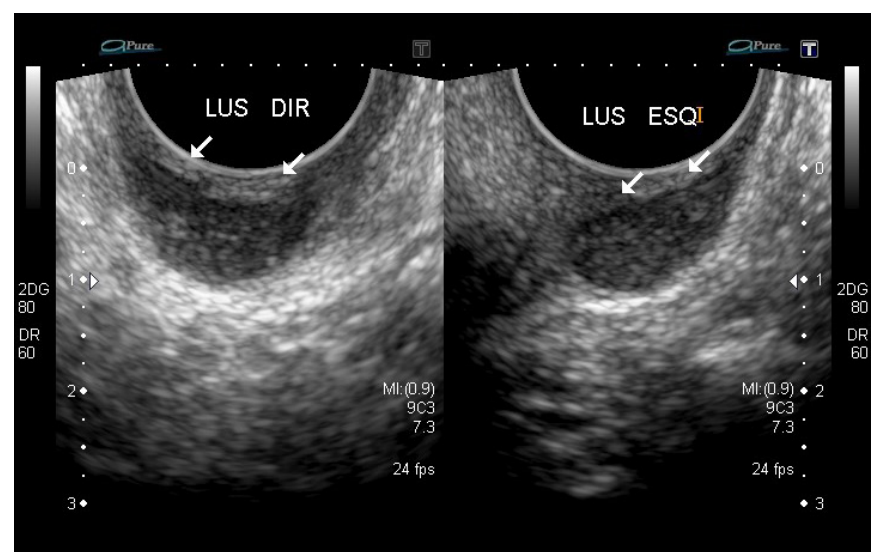

\section{Rectovaginal space}

The rectovaginal space is the region from the recto-uterine peritoneal fold (pouch of Douglas) and posterior vaginal wall to the level of the perineal reflection.

Rectovaginal endometriosis is the most severe form of endometriosis, presenting with a variety of symptoms that may include chronic pelvic pain, dysmenorrhea, deep dyspareunia, dyschezia, and rectal bleeding. Even though the gold standard for diagnosis is laparoscopy with histological confirmation, transvaginal/transrectal ultrasound is an option for pre-surgical diagnosis. ${ }^{12}$

Rectovaginal lesions are often extensions from retrocervical or posterior vaginal lesions, presenting as firm nodules that can be palpated at vaginal examination and seen as purplish nodular infiltrations through the speculum. At transvaginal US, lesions appear hypoechoic (Figure 4) and it is important to determine whether these have infiltrated or not the anterior rectal wall. ${ }^{1}$ 
Figure 4. Posterior vaginal fornix endometriosis infiltrating anterior rectal wall.

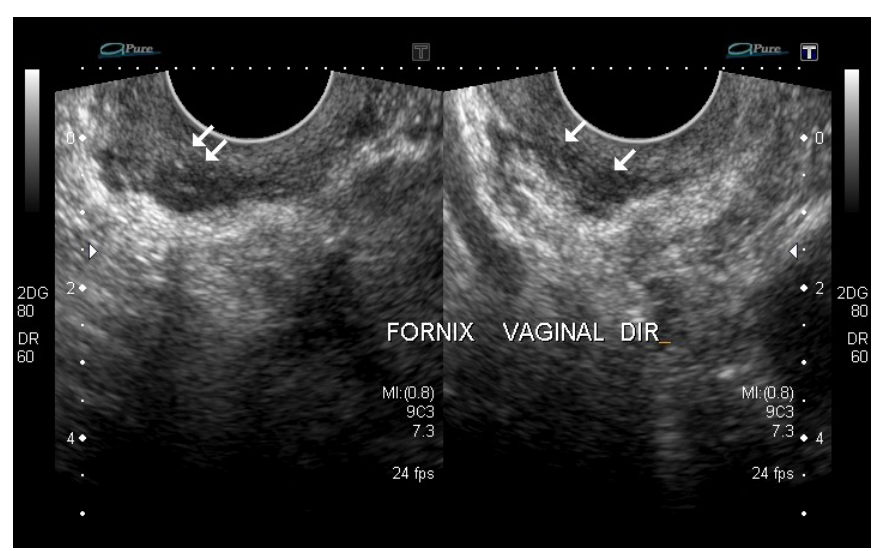

\section{Ovarian endometriosis}

The ovaries are affected in up to $80 \%$ of women who have endometriosis, corresponding to one of the most common sites of endometriosis. There are different types of manifestations of ovarian endometriosis: fibrotic implants associated with fibrous adhesions or endometriomas (chronic cysts with cyclic bleeding). ${ }^{13-15}$

Ovarian endometriomas are one of the classic phenotypes of endometriosis and are described as a common cause of pelvic pain, although the patient can also be asymptomatic. ${ }^{16}$ The mere presence of an endometrioma has been proposed to have a potential negative effect on fertility. ${ }^{17}$

Transvaginal US is known as the most common non-invasive method for diagnosis of endometriomas, and it is highly sensitive in the differential diagnosis of endometriomas. The images usually exhibit homogeneous, diffuse internal hypoechogenicity (Figure 5). Furthermore, septa, echogenic peripheral nodules, fluid-fluid levels and bright foci within the cysts may be observed. The cysts appear as a hypovascular image on color Doppler US, with no internal flow. Transvaginal US can also be useful to preoperative evaluation of adhesions. ${ }^{1,16}$ 'Kissing ovaries' is a well-known sign that can be found when the ovaries are stuck together as a result of extensive adhesion (Figure 6).

Figure 5. Diffuse internal hypoechogenicity and bright foci within the cysts.

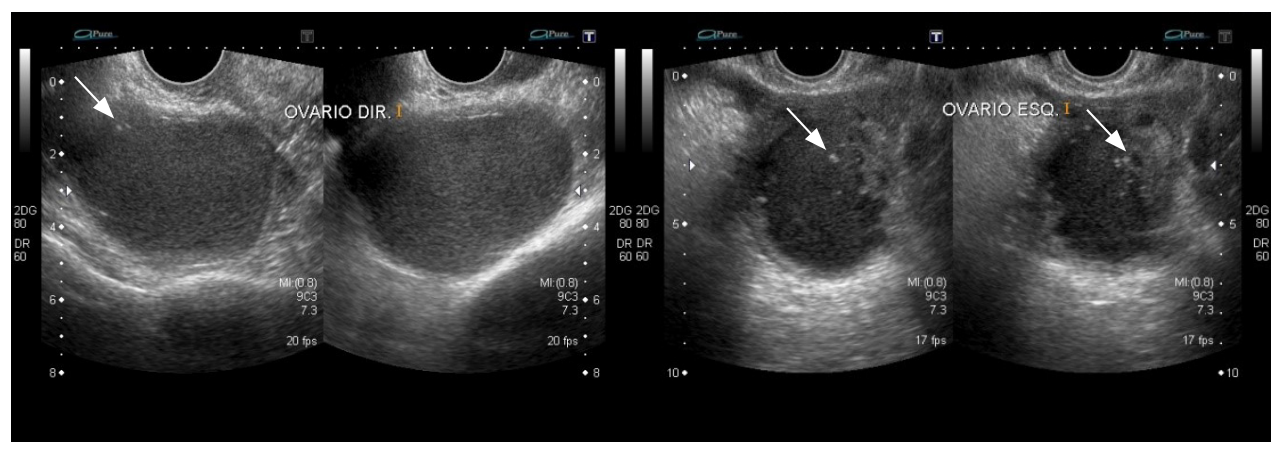

Figure 6. Kissing ovary sign as a consequence of adhesion and endometriosis.

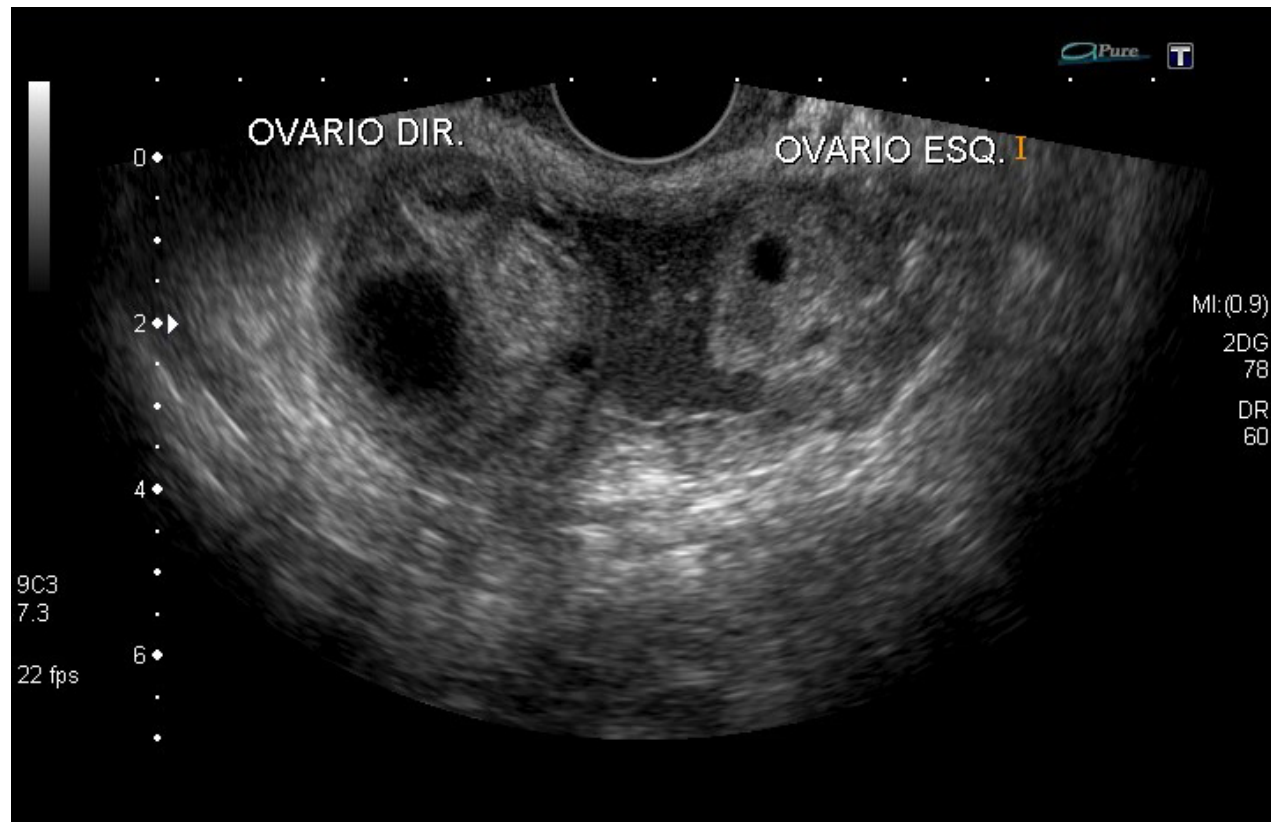




\section{Ureteral endometriosis}

The ureter is the second most affected site of urinary tract by endometriosis, with a ratio of bladder/ureter/kidney/ ureteral endometriosis of 40:5:1:1. In addition, the incidence of ureteral endometriosis is increasing over the years, what may correspond to the increasing rates of diagnosis due the greater availability of diagnostic methods such is ultrasonography. ${ }^{1,18}$

The diagnosis can be considered to be a challenge because of the lack of specific symptoms. Usually, patients have intense dysmenorrhea and dyspareunia, but pelvic pain and symptoms related to ovaries, rectovaginal septum, uterosacral ligaments and broad ligaments are also common. ${ }^{1,19}$

The following symptoms may be related to ureteral endometriosis such as hematuria associated with flank pain, cyclic gross hematuria and renal colic. Nevertheless, as the disease may be asymptomatic for a long time, the risk of hydronephrosis and renal failure is significant. ${ }^{18}$

Intrinsic and extrinsic ureteral involvements are also possible. Extrinsic involvement occurs in $80 \%$ of cases and is characterized by the progressive enclosure of the ureters by endometriotic tissue (Figure 7A). The intrinsic involvement is defined by infiltration of the muscularis of the ureteral wall. ${ }^{17}$

On transabdominal and transvaginal US, it is difficult to visualize the ureteral pathways, unless there is a dilatation. Transvaginal US is useful for diagnosing ureteral dilatation and for indicating the level of obstruction (Figure 7B). The ingestion of $300 \mathrm{ml}$ of water just before the exam allows the identification of the segment of the ureter between the iliac vessels and the ureterovesical junction. Hydronephrosis can be identified by renal US without difficulties (Figure 7C). ${ }^{1,20}$

Doppler US can show a jet that indicates unobstructed ureteral flow. ${ }^{1}$

Figure 7A. Hypoecoic pelvic mass compressing distal ureter (arrow).

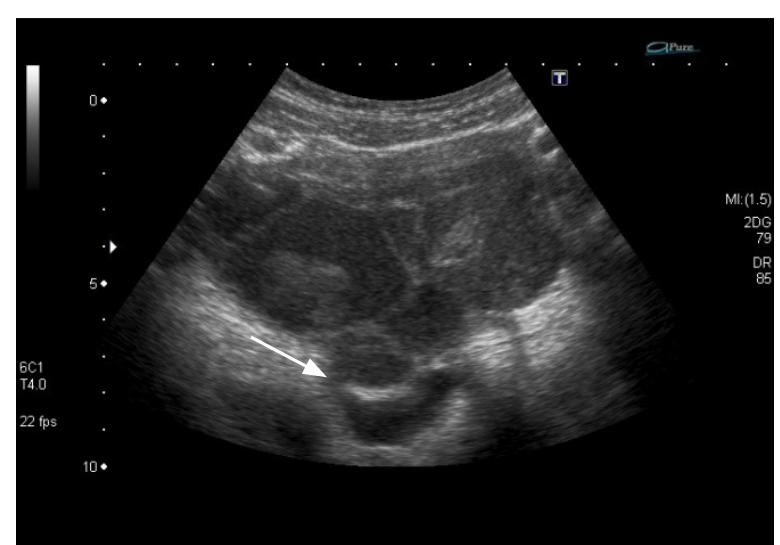

Figure 7B. Distal ureter stenosis (large arrow) and ureter distension (small arrows).

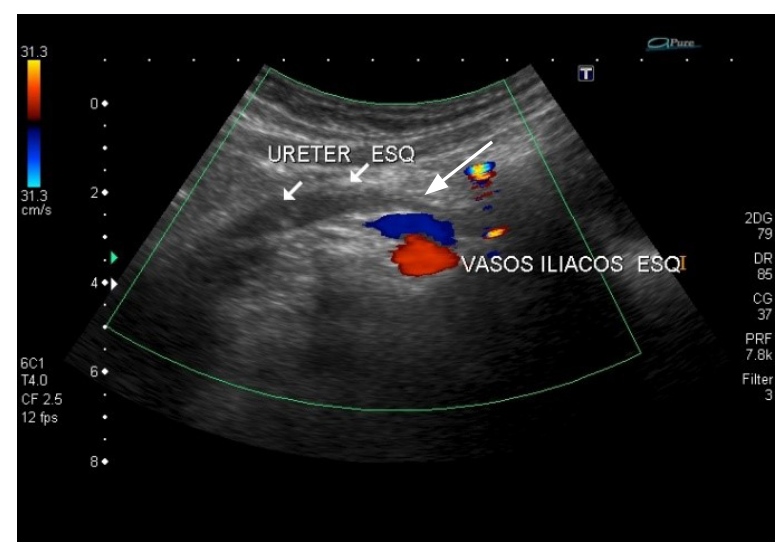

Figure 7C. Ureterohydronephrosis as a result of endometriosis.

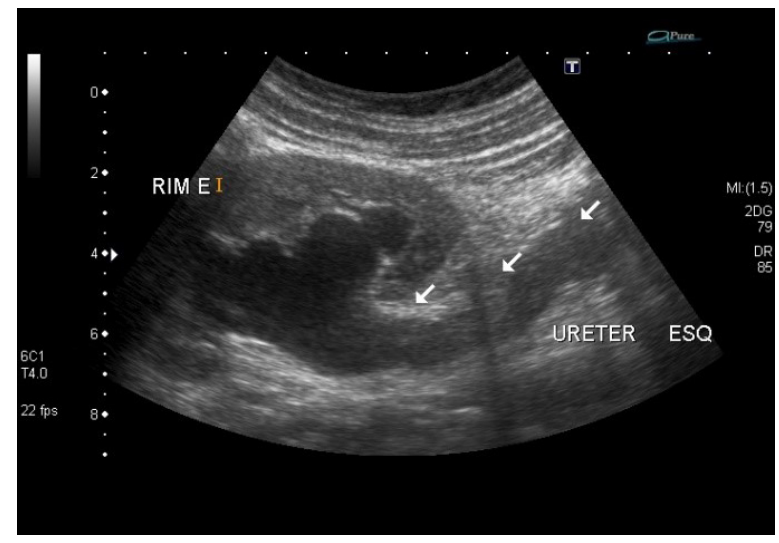

\section{Rectosigmoid colon endometriosis}

Gastrointestinal involvement by endometriosis can be observed in surgery in up to $37 \%$ of patients with endometriosis, and among the bowel locations the mostly affected anatomical site is the rectosigmoid colon. ${ }^{1,21}$

Classically, the symptoms of bowel endometriosis are cyclic, but they may be present in the premenstrual and periovulatory periods, but are less intense. Pain on defecation, bloating, and bowel cramping that is relieved by passing flatus or defecation are among the most common symptoms. The affected women can also have more frequent bowel movements during menses, but that does not promote diarrhea. Rectal bleeding during menses is rarely observed. $^{22}$

There has been an increasing in the preoperative diagnosis of rectosigmoid endometriosis worldwide. Transvaginal US after bowel preparation or transrectal US appear to have an important role in this context. Respectively, this method presents considerable sensitivities and specificities for endometriotic lesions evaluation, respectively 97 and 100\%, and 90 and $89,3 \%$, which are encouraging numbers. But it 
is necessary to emphasize that these diagnostic methods are entirely dependent on the radiologist experience, which is more relevant than the method itself and can be considered as a limitation of the method. ${ }^{22}$

Nodules in the descending colon, in the ileocecal region and in the rectosigmoid colon have the same appearance (Figure 8). ${ }^{23}$ The differential diagnosis includes rectal cancer and metastatic implants located in the bowel. ${ }^{23}$

Figure 8. Endometriotic nodules in the rectosigmoid colon (arrows).
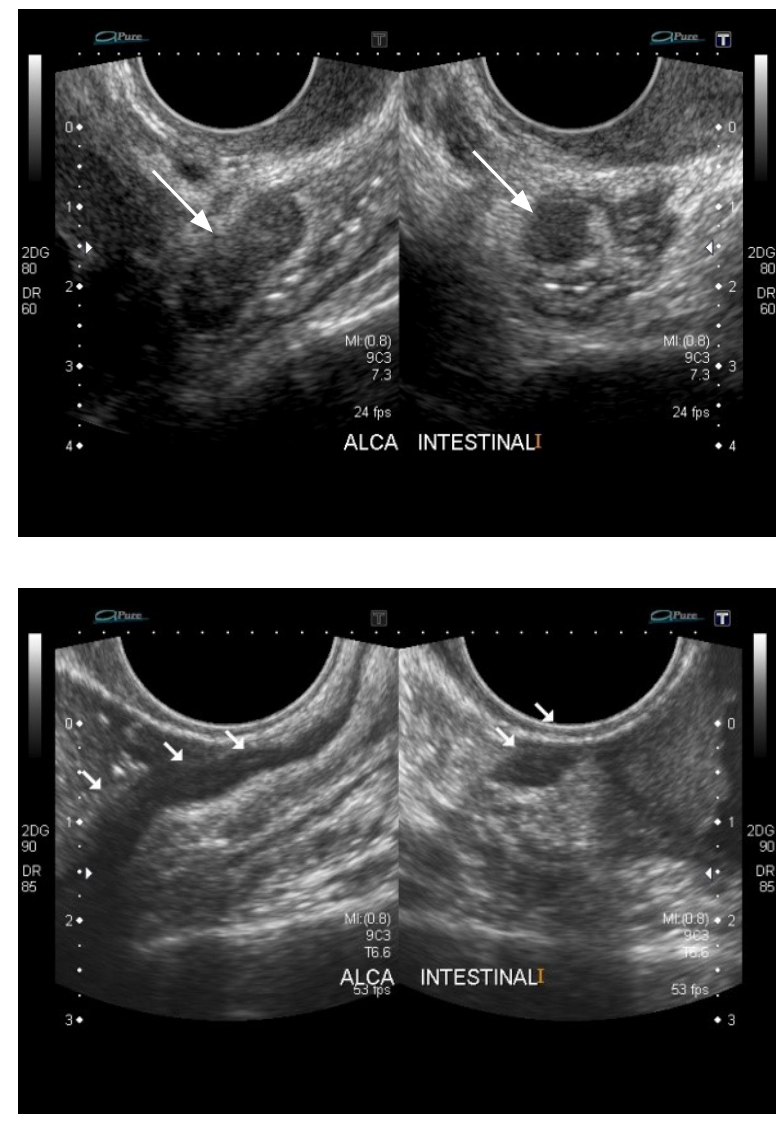

\section{REFERENCES}

1. Chamiè LP, Blasbalg R, Pereira RM, Warmbrand G, Serafini PC. Findings of pelvic endometriosis at transvaginal US, MR imaging, and laparoscopy. Radiographics. 2011;31(4):77-100.

2. Kondo W, Zomer MT, Pinto EP, Ribeiro R, Ribeiro MF, Trippia $\mathrm{CR}$, et al. Deep infiltrating endometriosis: imaging features and laparoscopic correlation. Journal of Endometriosis. 2011;3(4):197212.

3. Giudice LC. Endometriosis. N Engl J Med. 2010;362(25):238998 .

4. Tosti C, Pinzauti S, Santulli P, Chapron C, Petraglia F. Pathogenetic mechanisms of deep infiltrating endometriosis. Reprod Sci. 2015;22(9):1053-9.

\section{Vaginal endometriosis}

Vaginal endometriosis may be an incidental finding in asymptomatic patients. It is frequently related to endometriosis implants in other locations such as the retrocervical space and rectal lesions Postcoital spotting and dysmenorrhea may be present. Moreover, this condition is almost always associated with endometriosis in other sites, mainly rectal and retrocervical lesions. ${ }^{1}$

Transvaginal US shows hypoechoic vaginal endometriotic nodules with thickened appearance (Figure 9). The insertion of vaginal gel before the exam is relevant to visualize the posterior fornix due to distension of the vaginal lumen facilitating the visualization of the lesion. It is also useful to visualize the interface between the posterior cervical lip and vaginal wall. ${ }^{1}$

Figure 9. Transvaginal US: hypoechoic vaginal endometriotic nodules.

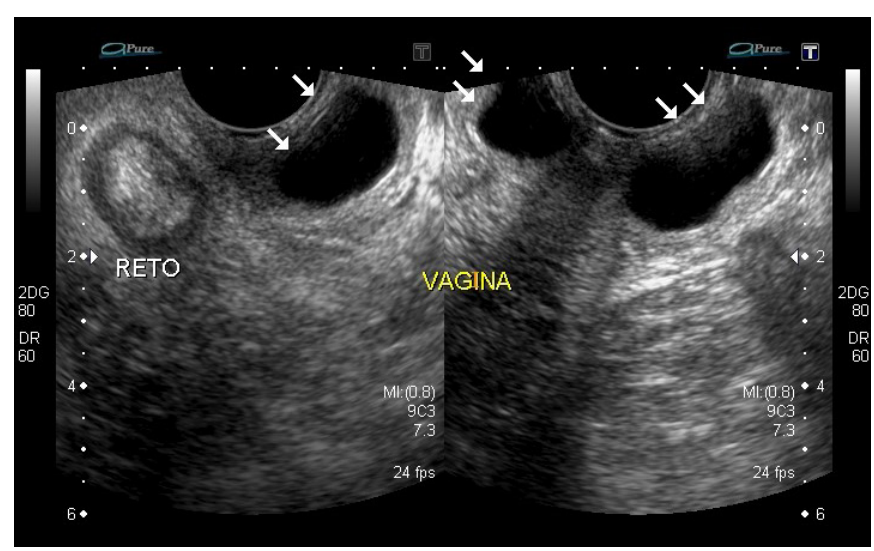

\section{CONCLUSION}

Transvaginal US is an inexpensive and affordable test, and is commonly the choice for diagnosing endometriosis. In this article, the performance of ultrasonography in the various extra-uterine sites that endometriosis can affect has been illustrated. Treatment and prognosis of endometriosis in each anatomical location were not covered in this article.

5. Bulun SE. Endometriosis. N Engl J Med. 2009;360(3):26879.

6. Guerriero S, Condous G, van den Bosch T, Valentin L, Leone FP, Van Schoubroeck D, et al. Systematic approach to sonographic evaluation of the pelvis in women with suspected endometriosis, including terms, definitions and measurements: a consensus opinion from the International Deep Endometriosis Analysis (IDEA) group. Ultrasound Obstet Gynecol. 2016;48(3):318-32.

7. Chamié LP, Pereira RM, Zanatta A, Serafini PC. Transvaginal US after bowel preparation for deeply infiltrating endometriosis: protocol, imaging appearances, and laparoscopic correlation. RadioGraphics. 2010;30(5):1235-49. 
8. Maggiore UL, Ferrero S, Candiani M, Somigliana E, Viganò P, Vercellini P. Bladder endometriosis: a systematic review of pathogenesis, diagnosis, treatment, impact on fertility, and risk of malignant transformation. Eur Urol. 2017;71(5):790-807.

9. Kumar S, Tiwari P, Sharma P, Goel A, Singh J, Vijay M, et al. Urinary tract endometriosis: review of 19 cases. Urol Ann. 2012;4(1):6-12.

10. Foti PV, Farina R, Palmucci S, Vizzini IA, Libertini N, Coronella $\mathrm{M}$, et al. Endometriosis: clinical features, MR imaging findings and pathologic correlation. Insights Imaging. 2018;9(2):149-72.

11. Levy AD, Shaw JC, Sobin LH. Secondary tumors and tumorlike lesions of the peritoneal cavity: imaging features with pathologic correlation: imaging features with pathologic correlation. Radiographics. 2009;29(2):347-73.

12. Moawad N, Caplin A. Diagnosis, management, and long-term outcomes of rectovaginal endometriosis. Int $\mathrm{J}$ Womens Health. 2013;5:753-63.

13. Clement MD. Diseases of the peritoneum (including endometriosis). 5. ed. New York: Springer Verlag; 2002.

14. Espada M, Alvarez-Moreno E, Pena MJ, Capio VM, Reid S, Condous G. Imaging techniques in endometriosis. J Endometr Pelvic Pain Disord. 2018;10(3):136-50.

15. Foti PV, Farina R, Palmucci S, Vizzini IA, Libertini N, Coronella $\mathrm{M}$, et al. Endometriosis: clinical features, MR imaging findings and pathologic correlation. Insights Imaging. 2018;9(2):149-72.
16. Pinto RM, Manso P, Pipa A. Endometriomas and ovarian reserve: general issues, treatment and impact in fertility. Acta Obstet Ginecol Port. 2013;7(3):199-207.

17. Goodman LR, Goldberg JM, Flyckt RL, Gupta M, Harwalker J, Falcone T. Effect of surgery on ovarian reserve in women with endometriomas, endometriosis and controls. Am J Of Obstet Gynecol. 2016;215(5):589.e1-589.e6.

18. Palla V, Karaolanis G, Katafigiotis I, Anastasiou I. Ureteral endometriosis: a systematic literature review. Indian J Urol. 2017;33(4):276-82.

19. Chapron C, Chiodo I, Leconte M, Amsellem-Ouazana D, Chopin $\mathrm{N}$, Borghese B, et al. Severe ureteral endometriosis: the intrinsic type is not so rare after complete surgical exeresis of deep endometriotic lesions. Fertil Steril. 2010;93(7):2115-20.

20. Carfagna P, Nardone CC, Nardone AC, Testa AC, Scambia G, Marana $R$, et al. Role of transvaginal ultrasound in evaluation of ureteral involvement in deep infiltrating endometriosis. Ultrasound Obstet Gynecol. 2018;51(4):550-55.

21. Macaffe $\mathrm{CH}$, Greer HL. Intestinal endometriosis: a report of 29 cases and a survey of the literature. Obstet Gynecol Surv. 1961;16(2):270-72.

22. Pereira RM, Zanatta A, Serafini PC, Redwine D. The feasibility of laparoscopic bowel resection performed by a gynaecologist to treat endometriosis. Curr Opin Obstet Gynecol. 2010;22(4):344-53.

23. Gonçalves MO, Dias JA Junior, Podgaec S, Averbach M, Abrão MS. Transvaginal ultrasound for diagnosis of deeply infiltrating endometriosis. Int J Gynecol Obstet. 2008;104(2):156-60.

\section{Como citar:}

Costa VL, Moreira MB, Farias LA, Costa JI. Ultrasonographic findings in pelvic endometriosis: literature review and pictorial essay. Rev Med UFC. 2020 out-dez;60(4):32-38. 